\section{ITC $3 / 46$}

Journal of Information Technology and Control

Vol. 46/ No. 3/2017

pp. 382-394

DOI 10.5755/j01.itc.46.3.16061

(C) Kaunas University of Technology

\section{A Hybrid Intelligent Optimal Control System Design for Wastewater Treatment Process}

Received 2016/08/16

Accepted after revision 2017/08/04

\title{
A Hybrid Intelligent Optimal Control System Design for Wastewater Treatment Process
}

\section{Junfei Qiao, Gaitang Han}

Beijing University of Technology, Faculty of Information Technology, 100 pingleyuan, Chaoyang District, Beijing, China, e-mail: junfeiq@bjut.edu.cn, hangaitang@emails.bjut.edu.cn

\section{Honggui Han, Cuili Yang, Wei Li}

Beijing Key Laboratory of Computational Intelligence and Intelligent System, 100 pingleyuan, Chaoyang District, Beijing, China

Corresponding author: junfeiq@bjut.edu.cn

Due to the characteristics of large lag and high nonlinearity, the optimizing operation of wastewater treatment process (WWTP) is difficult to be designed. To solve this problem, a control optimization system based on hybrid intelligent technology is proposed in this paper. This system includes a feed-forward compensator, a feedback supervision module, a pre-setting module and a soft-sensor module. To obtain the minimum energy consumption (EC) under effluent standards, the set-points of the dissolved oxygen concentration and nitrate nitrogen concentration are adjusted through feed-forward compensation, feedback correction and online estimation. Finally, the proposed approach is applied on the WWTP simulation model. Compared to the proportional-integral- derivative (PID) and data-driven adaptive optimal controller (DDAOC) methods, simulation results of the method proposed in this paper show better performance.

KEYWORDS: nonlinear, wastewater treatment, hybrid intelligent, optimization system.

\section{Introduction}

Because of the widespread water shortages in the world, the reuse of wastewater treatment is a common problem. Due to the characteristics of large lag and high nonlinearity, it is very difficult to control
$[12,13,14,26]$. The optimization target of WWTP is to obtain the minimum energy consumption that is the main part of the electric power consumption of WWTP under effluent standards. Moreover, the efflu- 
ent should be under standard, so the effluent quality (EQ) is another important index. EQ contends several factors that describe the wastewater treatment quality and process efficiency, such as total nitrogen $\left(\mathrm{N}_{\text {tot }}\right)$, chemical oxygen demand (COD), biochemical oxygen demand (BOD), total suspended solids (TSS) and ammonia nitrogen $\left(\mathrm{S}_{\mathrm{NH}}\right)$.

In a practical wastewater plant, many treatment processes are controlled by on-off control [24], closeloop proportional-integral (PI) [25] or by PID-based methods [27]. These conventional control methods are used to control the Underlying Running Module (URM) of the wastewater treatment process based on the feed-forward control loop and feedback control loop [28]. Then, the upper optimization module can ensure the overall performance requirements by optimizing the set-points [17]. In these conventional control schemes, the proportional, integral, differential parameters were always defied by human experience, or trial and error method. Therefore, the design of conventional controller may consume a lot of time. Moreover, in an actual situation, the set-point values were always decided by expert experience or by setting a high value, which has an appropriate amount of redundancy. For example, since the influent of pollutants concentration, water quantity and some other external factors may change frequently, and expert experience cannot always decide the set-point values online precisely when all the influential factors vary with time. Another problem is that if the set-point values were set as high values, some unnecessary operating costs would be increased.

In recent years, some optimization techniques, such as Adaptive dynamic programming [17], model predictive control [23], and so on, have been proposed for WWTP control. In these optimization techniques, the model of WWTP is very important. However, due to the characteristics of large time-varying and highly nonlinear, the precise mathematical model of WWTP is hard to achieve. The data-driven model based neural network can be used in these methods instead of the mathematical model. To achieve high learning efficiency and to reduce model complexity, the domain knowledge in complex system is adopted during the model design process [21]. To satisfy the requirements of nonlinear process model and the personified characteristics of intelligent technologies, some intelligent methods, such as fuzzy logic [9], artificial neural networks [18], intelligent evolution- ary algorithm [2] and case-based reasoning (CBR) [4], are used to achieve domain knowledge when solving the optimization problem in complex industrial process. For example, in [18], a neural network identifier was modeled to provide state information of WWTP for the neural network controller learning. In [4], a presetting model based reasoning technology was proposed to adjust the set-points of control loops for optimal operation of the shaft furnace in response to changes. These methods can adjust the parameters online in industry to optimize the complex control process. However, due to the characteristic of large lag, these intelligent control methods cannot be applied in WWTP directly.

In this paper, an intelligence hybrid control approach is proposed to optimize the WWTP. The proposed method will replace the expert experience by self-adjusting the proper set-points of dissolved oxygen and nitrate nitrogen with external environment changes. The system includes a pre-setting module (PSM), a supervision module (SVM), a feed-forward compensator (FFC) and an EQ soft-sensor module (ESM). FFC is used to compensate the set-points for PSM, ESM is employed to predict EQ values online. In addition, SVM is utilized to fix case solutions.

The rest part of this paper is as follows. The WWTP is described in Section 2. The intelligent optimalsetting control method is introduced in Section 3. The experimental results and analyses are described in Section 4. Finally, the concluding remarks are presented in Section 5.

\section{Problem Description}

\subsection{Process Description}

The wastewater treatment process, using activated sludge process to clear pollutants in sewage, is a typical nonlinear and time-varying complex dynamic system [15]. Because of these complex characteristics, the WWTP is hard to be controlled. The illustration of a WWTP is shown in Figure 1, and the corresponding parameters of Figure 1 are described in Table 1. According to Figure 1, the WWTP consists of two parts. The first part, called biological reactor, consists of five units, and the second part, called settler, consists of a ten layers sedimentation tank. 
Figure 1

Schematic diagram of wastewater treatment system

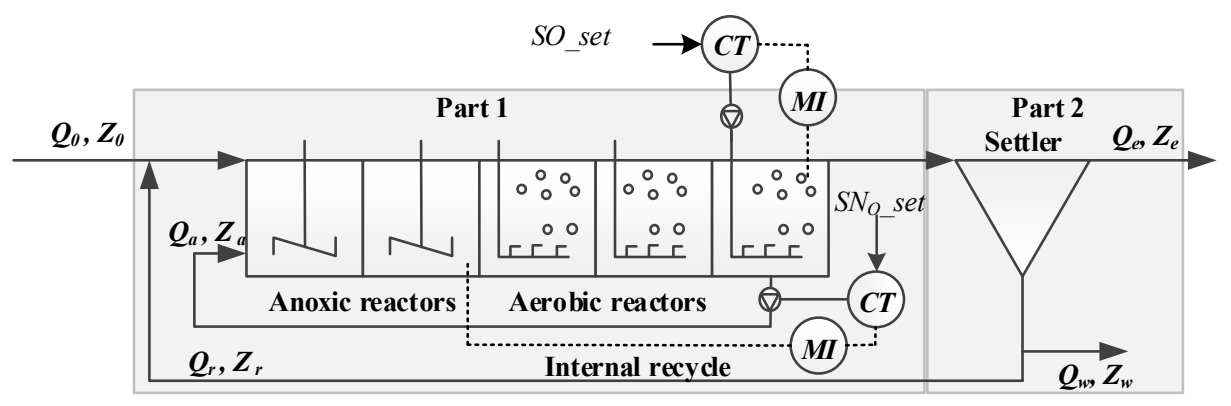

Table 1

Description of variables in Figure 1

\begin{tabular}{|c|c|}
\hline Symbol & Description \\
\hline SO_set & set-point of dissolved oxygen \\
\hline$S N_{O} \_$set & set-point of nitrate nitrogen \\
\hline$k_{L a}$ & oxygen transfer coefficient \\
\hline$C T$ & controller \\
\hline$M I$ & measurement instrument \\
\hline$Z_{0}$ & influent component \\
\hline$Z_{a}$ & internal flow component \\
\hline$Z_{r}$ & external flow component \\
\hline$Z_{w}$ & sludge flow component \\
\hline$Z_{e}$ & effluent component \\
\hline$Q_{0}$ & influent flow \\
\hline$Q_{a}$ & internal flow \\
\hline$Q_{r}$ & external flow \\
\hline$Q_{w}$ & sludge flow \\
\hline$Q_{e}$ & effluent flow \\
\hline
\end{tabular}

The denitrification biological nitrogen (AO) removal method is a commonly used technology in WWTP. In this process, the influent water from urban water supply network flow into biological reactor, which is the main stage to eliminate organic pollutants by biochemical reactions. Then, the water flow into settler in which the wastewater is clarified by physical set- tlement. Finally, wastewater is discharged into the receiving water body and part of the sludge returns to biochemical reaction tank to save costs.

The removal of nitrogen element is the main part of the activated sludge system. The biological removal of nitrogen transformation generally includes assimilation, ammoniation, nitrification, denitrification and other biochemical reactions in WWTP, in which the nitrification and denitrification biochemical reactions process can be controlled.

\subsection{Analysis of the Control Problem}

In the WWTP system which as shown in Figure 1, there are two important indices, namely the EC and the EQ [17]. The EC, including aeration energy consumption and pumping energy consumption, is the commonly used energy consumption of WWTP. The $\mathrm{EQ}$, whose expression includes $\mathrm{S}_{\mathrm{NH}}, \mathrm{N}_{\text {tot }}, \mathrm{COD}, \mathrm{BOD}$ and TSS, is another important index which shows the performance of WWTP directly.

For a given WWTP which as shown in Figure 1, there exist some inherent complex characteristics. Firstly, since the biochemical reactions exist in WWTP and the main disturbed conditions, such as influent flow and influent component, change sharply with time, the control process of wastewater treatment is extremely difficult. Secondly, the EQ is disadvantageous for the wastewater treatment, when its value is oversize or undersize compared with the effluent standard. Therefore, in contrast to the fixed set-point value control, the set-point value needs to change with the state of the WWTP. In addition, when the 
pollutant concentration of influent is at a high degree, the set-point value of relative control loop is always set as a large value. Otherwise, the set-point value of relative control loop is set as a low value.

\section{The HIOC System for Wastewater Treatment}

If the influent conditions are stable and the fixed set-point value is decided through the extensive operational experience, the set-point value needs not change with time. Unfortunately, the influent conditions often vary with time, and the expert cannot pay more attention to overall process all the time. This phenomenon leads to that the fixed operating point method cannot obtain good performance for the final indices.

Based on the above issues, a hybrid intelligent optimal control (HIOC) system is designed in this paper to control WWTP. This system is formed by the hybrid intelligent techniques, including artificial neural network (ANN), rule-based reasoning (CBR) and rule inference. The framework of HIOC system is shown in Figure 2. This system is established by an underlying control module (ULCM), a CBR-based pre-setting module (CBR-PSM) and a feed-forward compensator module (FFCM).

The variables in Figure 2 are described in Table 2. The human experience method can be replaced by the HIOC system to auto-adjust the set-point values of $D_{\mathrm{O}}$ and $S_{\mathrm{NO}}$ under the variations of influent flow and influent component. The major role of each part is described as follows:

1 The CBR-PSM is utilized to decide the preset points of $D_{O}$ and $S_{\text {NO }}$ by the CBR technique with the variations of influent flow and influent component.

2 The SVM is used to fix case solutions based on the rule inference method when the effluent value cannot fulfill the inference index.

3 The ESM is utilized to predict the effluent value by the ANN technique.

4 The FFCM is used to compensate the deviation of set-point values that are caused by the variation in boundary conditions.

In the optimization process of WWTP, the similarity between the influent conditions and the problem description of the case will be calculated by the CBRPSM. The closest cases can be treated as the preset points for the lower level controllers. Then, the FFC is used to advance compensate the bias between the predict values and the expected values of effluent in-

\section{Figure 2}

The HIOC system of wastewater treatment process

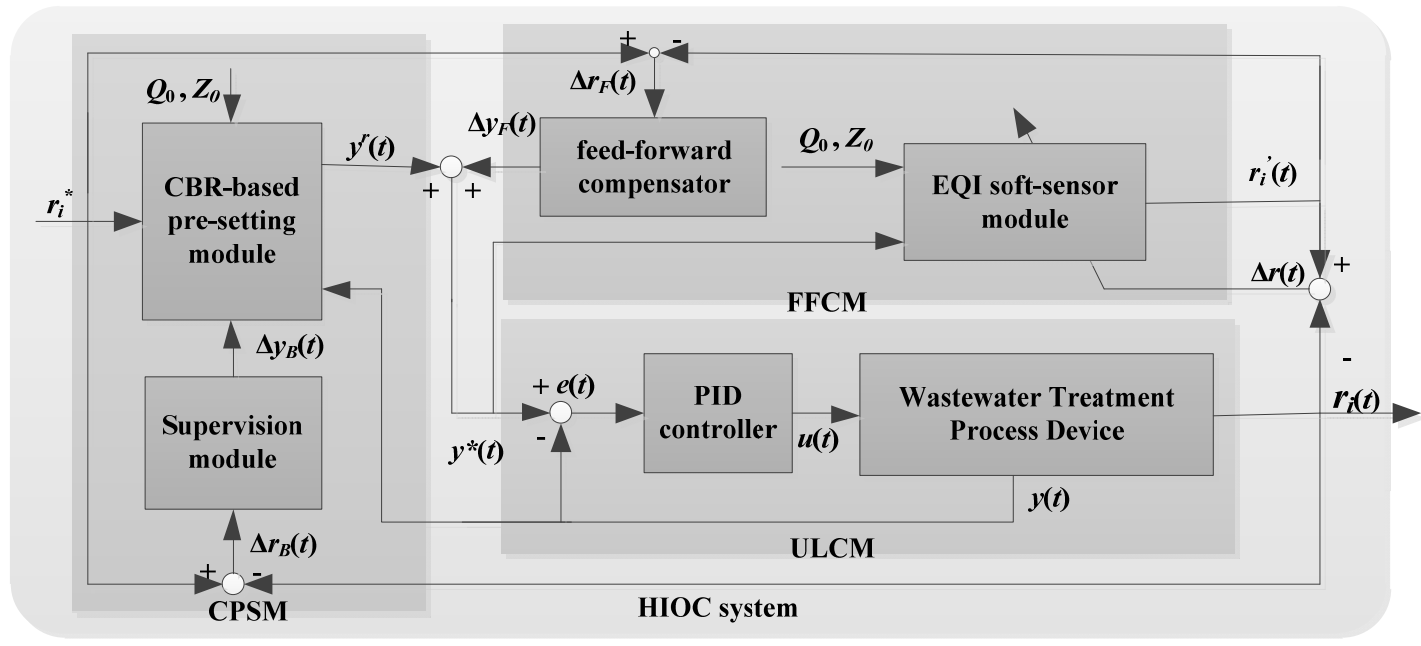




\section{Table 2}

Description of variables in Figure 2

\begin{tabular}{c|l}
\hline Symbol & \multicolumn{1}{|c}{ Description } \\
\hline$y$ & the measured values of $\mathrm{D}_{\mathrm{O}}$ and $\mathrm{S}_{\mathrm{NO}}$ \\
\hline$y^{r}$ & the preset points of $\mathrm{D}_{\mathrm{O}}$ and $\mathrm{S}_{\mathrm{NO}}$ \\
\hline$y^{*}$ & the set-points of $\mathrm{D}_{\mathrm{O}}$ and $\mathrm{S}_{\mathrm{NO}}$ \\
\hline$y_{F}$ & the feed-forward compensate values of $\mathrm{D}_{\mathrm{O}}$ and $\mathrm{S}_{\mathrm{NO}}$ \\
\hline$y_{B}$ & the case solutions' correction values of $\mathrm{D}_{\mathrm{O}}$ and $\mathrm{S}_{\mathrm{NO}}$ \\
\hline$r$ & the measured values of effluent index \\
\hline$r^{\prime}$ & the predict values of effluent index \\
\hline$r^{*}$ & the expected values of effluent index \\
\hline$r_{F}$ & the feed-forward bias of effluent index \\
\hline$r_{B}$ & the feedback bias of effluent index \\
\hline$u$ & manipulated variables \\
\hline$e$ & the error between measured values and set- \\
\hline$\Delta$ & points of $\mathrm{D}_{\mathrm{O}}$ and $\mathrm{S}_{\mathrm{No}}$ \\
\hline
\end{tabular}

dex. Finally, the SVM is utilized to evaluate the case solutions before a delay period (Td) which is caused by biochemical reaction in WWTP.

In this paper, our main work is described as follows. Firstly, the HIOC system is designed to achieve knowledge automatically from the wastewater treatment condition by the technology of case revision. Secondly, an embedded hybrid model is used to calculate the preset points for the lower level control layer. The model is composed of CBR module and rule-based reasoning (RBR) module. Finally, the delay information from WWTP to the decision-making process of the preset points is considered.

\section{Realization of the HIOC System}

\subsection{CBR-Based Pre-Setting Module}

Case-Based reasoning [4] is generally suitable for the cases where precise physical models and knowledge on the concerned process are not available. Its basic principle is that the similar problem scenario has similar solutions. The CBR technology includes case representation, case retrieval, case matching, case reuse, case revision as well as case retention. The reasoning flowchart is shown in Figure 3.

\section{Figure 3}

Reasoning flow of case reasoning

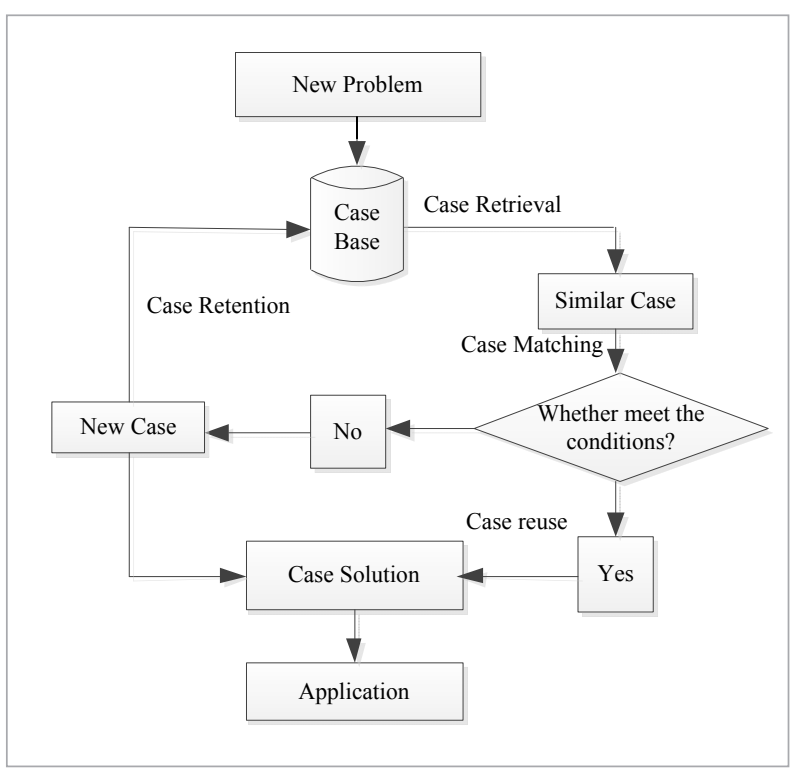

\subsubsection{Case Representation}

The general methods of case representation include the property characteristic value description method [16], the frame representation method [6] and the object-oriented method [3]. In this paper, the property characteristic value description method [16] was chosen as the form of case representation due to its simple and clear characteristic. It can be shown as follows:

$$
C_{k}:<X_{k} ; Y_{k}>, \quad k=1,2, \ldots, n
$$

where $\mathrm{C}$ denotes case; $k$ and $n$ represent the $k$ th case and the total number of cases, respectively; $X$ and $Y$ are the problem situation of case and the case solutions, respectively.

\subsubsection{Case Retrieval and Case Matching}

Due to the simplicity and practicability [5], the nearest neighbor method is designed to search for a similar case. In this paper, the similarity equation in the current WWTP and the $k$ th case of the case base could be expressed as follows: 


$$
\left\{\begin{array}{l}
s_{k}=1-\sum_{i=1}^{4} w_{i} \operatorname{sim}\left(x_{i}, x_{i, k}\right) \\
\operatorname{sim}\left(x_{i}, x_{i, k}\right)=\frac{\left|x_{i}-x_{i, k}\right|}{\max \left(x_{i}, x_{i, k}\right)}
\end{array}\right.
$$

where $\operatorname{sim}\left(x_{i}, x_{i, k}\right)$ represents the similarity between $X$ and $X_{k} . w_{i}$ denotes case feature weight of the $i$-th expression attribute attained by expert experience. The constraint condition is defined by

$$
\sum_{i=1}^{4} w_{i}=1 \quad \text { and } \quad w_{i} \geq 0 .
$$

If the following condition [31]

$$
s_{k} \geq s_{\text {th }}=\left\{\begin{array}{l}
w_{t h}, \text { if } \max _{k=1, \ldots, n}\left(s_{k}\right) \geq w_{t h} \\
\max _{k=1, \ldots, n}\left(s_{k}\right), \text { if } \max _{k=1, \ldots, n}\left(s_{k}\right)<w_{t h}
\end{array}\right.
$$

is satisfied, the $k$-th case can be treated as the matching case, where $w_{t h}$ is a threshold to analyse the degree of similar case.

\subsubsection{Case Reuse}

If the number of cases that satisfy the inequality (4) is $m$, the case solution of current wastewater treatment can be calculated by combining the solutions of the corresponding cases. The formula of case reuse is shown as follows:

$$
Y^{r}=\left\{\begin{array}{l}
Y_{h}^{r}, \text { if } \max _{k=1, \ldots, n}\left(s_{k}\right)<w_{t h} \text { and } s_{h}=\max _{k=1, \ldots, n}\left(s_{k}\right) \\
\frac{1}{m} \sum_{j=1}^{m} Y_{j}^{r}, \text { if } \max _{k=1, \ldots, n}\left(s_{k}\right) \geq w_{t h}
\end{array}\right.
$$

\subsubsection{Case Revision and Case Retention}

Case revision and case retention are used to ensure the quality of case base. If the effluent quality beyond the expected field after the wastewater system runs with the preset points, the previous $Y$ needs to be revised. Otherwise, there is no operation. Here, it needs to emphasize that the revise time of case revi- sion should be set as a delay time $t_{d}$. The parameter $t_{d}$ is the time of the wastewater flows from influents inlet to effluent outlet. Moreover, the evaluation process of the effluent quality can only be used to revise the previous application cases rather than real-time compensation which is important for large-lag systems, such as WWTP system.

\subsection{EQ Soft-Sensor Module}

In the optimal control of wastewater treatment, effluent quality cannot be measured online with conventional tools due to the biochemical reactions [19]. Recently, to overcome the measurement problems of critical variables in complex system, some soft-sensor method, based on neural network technology, was used $[10,20,29]$. Especially, the feed-forward neural network (FNN) is widely used for soft-sensor modeling in complex nonlinear dynamic system because its effectiveness and simplicity $[8,11,30]$. In [18], the identifier and controller based FNN was designed to control WWTP. This proposed method had good performance. In [19], an improved fuzzy neural network (TSFNN) was introduced to predict biochemical oxygen demand values by the soft computing method. The algorithm presents a better approximation performance than some other methods. In [8], a self-organizing radial basis function neural network (SORBF) based predictive control method was proposed for controlling the DO concentration in a WWTP. The proposed SORBF can vary its structure dynamically to maintain prediction accuracy. Due to the successful application of FNN described above, the FNN-based soft-sensor method is utilized in this paper to measure the value of EQ online.

\subsubsection{Structure of FNN}

The structure schematic representation of FNN is shown in Figure 4. $\mathrm{X}=\left[x_{1}, x_{2}, \ldots, x_{m}\right]^{\mathrm{T}}$ represent the influent component and set-points of $\mathrm{D}_{\mathrm{O}}$ and $\mathrm{S}_{\mathrm{NO}}$. The variables $\mathrm{Y}=\left[y_{1}, y_{2}, \ldots, y_{n}\right]^{\mathrm{T}}$ denote the estimated value of $\mathrm{EQ} . H$ is the number of hidden nodes. The symbol $\theta$ stands for the nonlinear activation function that is selected as the sigmoid function. The parameters $w_{i j}{ }^{1}$ and $w_{i j}{ }^{2}$ represent the $j$ th weight of the $i$ th input node and the $j$ th weight of the $i$ th hidden node, respectively. 
Figure 4

Structure schematic representation of FNN

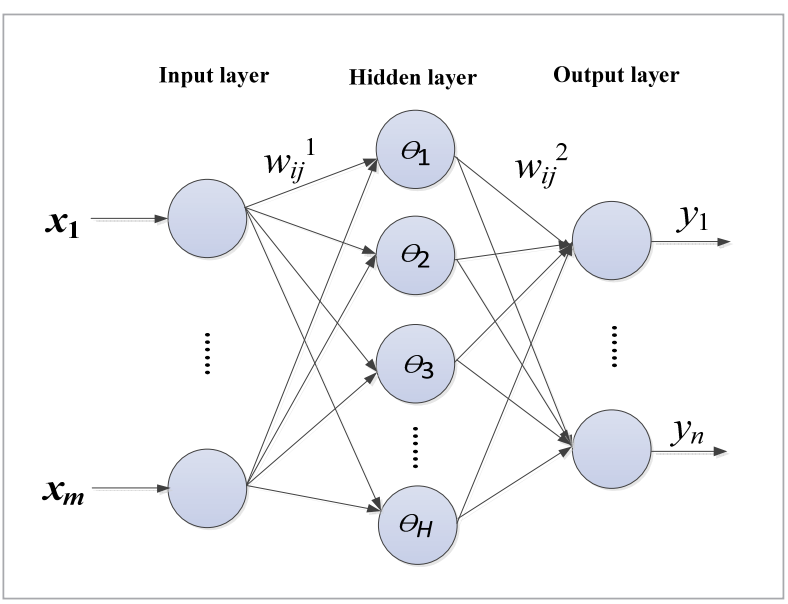

\subsubsection{FNN Learning Algorithm}

The back-propagation algorithm is employed as the learning algorithm of FNN. The training objective function is shown as follows:

$$
J(k)=\frac{1}{2}(\mathbf{e}(k))^{2} .
$$

According to the back-propagation algorithm, the online update formulas of the weights $w_{i j}{ }^{1}$ and $w_{i j}{ }^{2}$ can be expressed as follows:

$$
\begin{aligned}
w_{i j}^{1}(k+1) & =w_{i j}{ }^{1}(k)-\Delta w_{i j}{ }^{1}(k) \\
& =w_{i j}{ }^{1}(k)-\eta_{1}(k) \frac{\partial J(k)}{\partial w_{i j}{ }^{1}(k)} \\
w_{i j}{ }^{2}(k+1) & =w_{i j}{ }^{2}(k)-\Delta w_{i j}{ }^{2}(k) \\
& =w_{i j}{ }^{2}(k)-\eta_{2}(k) \frac{\partial J(k)}{\partial w_{i j}{ }^{2}(k)}
\end{aligned}
$$

where $e(k)=y(k)-y^{\prime}(k), \eta$ and $\Delta w$ represent the learning rate and the increment of the weight $\mathrm{w}$, respectively.

\subsection{Feedback Supervision Module}

Due to the time-varying characteristic of WWTP, the case solution stored in case base cannot solve all possible problem conditions in WWTP. Moreover, the case solutions may not be the optimal settings since the treatment environment is time-varying. Given the above analysis, the feedback supervision module should be adopted to evaluate and adjust the case solutions that cannot satisfy the indicators of wastewater treatment control system. The rule-based reasoning technology is an effective and practical method in the field of artificial intelligence [1, 7]. Because such a reasoning technology can provide comprehensible rules, rule-based reasoning technology can be validated by manual inspection. In this paper, the rule-based reasoning is treated as the feedback supervision module to evaluate and adjust the case solutions. The production rule is used to the processing mode of rule-based reasoning, which is shown as follows:

\section{IF/WHEN Conditions THEN \\ Actions}

The reasoning rules are decided by the experimental study, which is shown as Figure 3 in [17]. According to the experimental study, the operational rules can be shown in Table 3 . In this table, $t_{d}$ is the time of the wastewater flows from influents inlet to effluent outlet. $\Delta r_{\mathrm{B} 1}$ and $\Delta r_{\mathrm{B} 2}$ are the error between the setting indicators and the actual value of ammonia and total nitrogen, respectively. $\Delta y_{\mathrm{B} 1}$ and $\Delta y_{\mathrm{B} 2}$ represent the adjustment amount of the DO set-point and $\mathrm{S}_{\mathrm{NO}}$ setpoint, respectively. Parameters $k_{m 1}=0.1$ and $k_{m 2}=0.1$ are determined by experience. It should be noted that the inference rules would only work for a lag period in the previous case correction, and not act on the set value of real-time correction.

\subsection{Feed-Forward Compensator}

The feed-forward compensator is used to compensate the set-points of the $\mathrm{D}_{\mathrm{O}}$ and $\mathrm{S}_{\mathrm{NO}}$. The measure process of effluent quality is time consuming, which makes the control system unable to control the wastewater treatment process on time. On the other hand, the error can be predicted in advance by the ESM while the FFC can compensate the error in advance. The design structure of FFC is similar to the rule reasoning of feedback supervision module. 
Table 3

Operation rules of feedback supervision module

\begin{tabular}{l|l|l|l}
\multicolumn{1}{c|}{ Rules } & \multicolumn{1}{c|}{ If } & \multicolumn{1}{c}{ Then } \\
\hline Rule 1 & $\Delta r_{\mathrm{B} 1}(k)>0$ and $\Delta r_{\mathrm{B} 2}(k)>0$ & $\Delta y_{\mathrm{B} 1}\left(k-t_{d}\right)=-\left|\Delta r_{\mathrm{B} 1}(k)\right| k_{m 1}$ & $\Delta y_{\mathrm{B} 2}\left(k-t_{d}\right)=-\left|\Delta r_{\mathrm{B} 2}(k)\right| k_{m 2}-0.1\left|\Delta r_{\mathrm{B} 1}(k)\right| k_{m 1}$ \\
\hline Rule 2 & $\Delta r_{\mathrm{B} 1}(k)>0$ and $\Delta r_{\mathrm{B} 2}(k)=0$ & $\Delta y_{\mathrm{B} 1}\left(k-t_{d}\right)=-\left|\Delta r_{\mathrm{B} 1}(k)\right| k_{m 1}$ & $\Delta y_{\mathrm{B} 2}\left(k-t_{d}\right)=-0.1\left|\Delta r_{\mathrm{B} 1}(k)\right| k_{m 1}$ \\
\hline Rule 3 & $\Delta r_{\mathrm{B} 1}(k)>0$ and $\Delta r_{\mathrm{B} 2}(k)<0$ & $\Delta y_{\mathrm{B} 1}\left(k-t_{d}\right)=-\left|\Delta r_{\mathrm{B} 1}(k)\right| k_{m 1}$ & $\Delta y_{\mathrm{B} 2}\left(k-t_{d}\right)=\left|\Delta r_{\mathrm{B} 2}(k)\right| k_{m 2}-0.1\left|\Delta r_{\mathrm{B} 1}(k)\right| k_{m 1}$ \\
\hline Rule 4 & $\Delta r_{\mathrm{B} 1}(k)=0$ and $\Delta r_{\mathrm{B} 2}(k)>0$ & $\Delta y_{\mathrm{B} 1}\left(k-t_{d}\right)=0$ & $\Delta y_{\mathrm{B} 2}\left(k-t_{d}\right)=-\left|\Delta r_{\mathrm{B} 2}(k)\right| k_{m 2}$ \\
\hline Rule 5 & $\Delta r_{\mathrm{B} 1}(k)=0$ and $\Delta r_{\mathrm{B} 2}(k)=0$ & $\Delta y_{\mathrm{B} 1}\left(k-t_{d}\right)=0$ & $\Delta y_{\mathrm{B} 2}\left(k-t_{d}\right)=0$ \\
\hline Rule 6 & $\Delta r_{\mathrm{B} 1}(k)=0$ and $\Delta r_{\mathrm{B} 2}(k)<0$ & $\Delta y_{\mathrm{B} 1}\left(k-t_{d}\right)=0$ & $\Delta y_{\mathrm{B} 2}\left(k-t_{d}\right)=\left|\Delta r_{\mathrm{B} 2}(k)\right| k_{m 2}$ \\
\hline Rule 7 & $\Delta r_{\mathrm{B} 1}(k)<0$ and $\Delta r_{\mathrm{B} 2}(k)>0$ & $\Delta y_{\mathrm{B} 1}\left(k-t_{d}\right)=\left|\Delta r_{\mathrm{B} 1}(k)\right| k_{m 1}$ & $\Delta y_{\mathrm{B} 2}\left(k-t_{d}\right)=-\left|\Delta r_{\mathrm{B} 2}(k)\right| k_{m 2}+0.1\left|\Delta r_{\mathrm{B} 1}(k)\right| k_{m 1}$ \\
\hline Rule 8 & $\Delta r_{\mathrm{B} 1}(k)<0$ and $\Delta r_{\mathrm{B} 2}(k)=0$ & $\Delta y_{\mathrm{B} 1}\left(k-t_{d}\right)=\left|\Delta r_{\mathrm{B} 1}(k)\right| k_{m 1}$ & $\Delta y_{\mathrm{B} 2}\left(k-t_{d}\right)=0.1\left|\Delta r_{\mathrm{B} 1}(k)\right| k_{m 1}$ \\
\hline Rule 9 & $\Delta r_{\mathrm{B} 1}(k)<0$ and $\Delta r_{\mathrm{B} 2}(k)<0$ & $\Delta y_{\mathrm{B} 1}\left(k-t_{d}\right)=\left|\Delta r_{\mathrm{B} 1}(k)\right| k_{m 1}$ & $\Delta y_{\mathrm{B} 2}\left(k-t_{d}\right)=\left|\Delta r_{\mathrm{B} 2}(k)\right| k_{m 2}+0.1\left|\Delta r_{\mathrm{B} 1}(k)\right| k_{m 1}$ \\
\hline
\end{tabular}

\section{Experiment Studies}

\subsection{Evaluation Indexes}

The proposed HIOC system is used to optimize the set-points in WWTP. The data come from the benchmark simulation model 1 (BSM1) which is used to drive the test verification environment. The BSM1 has defined the performance evaluating criteria [22], which are shown in the following formulas:

$$
\begin{aligned}
& A E(k)=\frac{S_{o}^{s a t}}{T \cdot 1.8 \cdot 1,000} \int_{k T}^{(k+1) T} V_{5} K_{L} a_{5}(\mathrm{t}) d t \\
& P E(k)=\frac{1}{T} \int_{k T}^{(k+1) T} 0.004 Q_{a}(t) d t \\
& E Q(k)= \\
& \frac{1}{T \cdot 1,000} \int_{k T}^{(\mathrm{k}+1) T}\left(\begin{array}{l}
B_{S S} \cdot S S_{e}(t)+B_{\mathrm{COD}} \cdot C O D_{e}(t)+B_{\mathrm{NO}} \cdot S_{\mathrm{NO}, \mathrm{e}}(t) \\
+B_{\mathrm{Nkj}} \cdot S_{\mathrm{Nkj,e}}(t)+B_{\mathrm{BOD} 5} \cdot \mathrm{BOD}_{\mathrm{e}}(t)
\end{array}\right)
\end{aligned}
$$

where $A E$ and $P E$ are aeration energy consumption and pumping energy consumption, respectively. $E Q$ is the fines to be paid due to the discharge of pollution in the receiving water bodies. Thus, the total cost can be defined as follows:

$$
\operatorname{COST}=a_{1} A E+a_{2} P E+a_{3} E Q
$$

where $a_{1}, a_{2}$ and $a_{3}$ are the turning factors, respectively. Normally, the ratio of these coefficients is 1: 1: 1 [17]. However, the ratio can also be adjusted according to the importance of energy consumption and fines.

\subsection{Parameter Initialization}

The number of the initial cases in case library is set to 15 . Two independent proportional-integral-derivative (PID) controllers are used to control the actual output values to track the set-points generated by CBR-PSM. The proportional, integral and differential coefficients of PID controller for dissolved oxygen control are 200, 15 and 2, respectively. The proportional, integral and differential coefficients of PID controller for nitrate nitrogen control are 20000, 5000 and 400, respectively. These parameters of PID were obtained by trial and error method. The structure of FNN was chosen as 6-12-2.

\subsection{Results and Analysis}

The HIOC system was tested in dry weather conditions (the dry weather file includes 14 days data, in which the data of the first seven days are for training, the data of the latter seven days are for testing). The case generating curve is shown in Figure 5. It shows that the case number reached forty-one on the sixth day. 
Figure 5

The case numbers

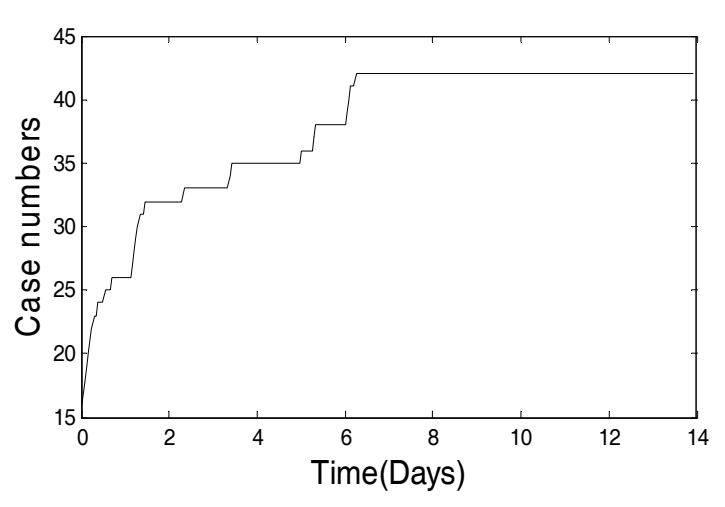

The comparison of the effluent quality indices between the HIOC scheme and the traditional PID control scheme is shown in Figure 6. Referring to this figure, we can make a few conclusions. Firstly, when the effluent ammonia nitrogen (SNH) could reach the standard of discharge, the actual output value of HIOC scheme was closer to the standard line than that of the PID control scheme, which means the HIOC needs less energy than the PID control scheme. Secondly, compared to the PID control scheme, a better quality of effluent Ntot can be achieved by the HIOC scheme, which means the HIOC scheme needs less fines due to the discharge of pollution than the PID control scheme. Finally, the quality of effluent chemical oxygen demand and biochemical oxygen demand has little difference under the HIOC scheme and the traditional PID control scheme. The optimization results of set-points are shown in Figure 6, which shows that the set-points could be adjusted with the change of the influent flow rate and the pollutions concentration.

Table 4 shows the numerical comparison between the HIOC and the PID control schemes. In the PID control scheme, the set-points of the DO and SNO were set as $2 \mathrm{mg} / \mathrm{L}$ and $1 \mathrm{mg} / \mathrm{L}$. Compared with the PID control scheme, the average value of the set-point of the

\section{Figure 6}

Comparison of effluent quality indices between HIOC and PID

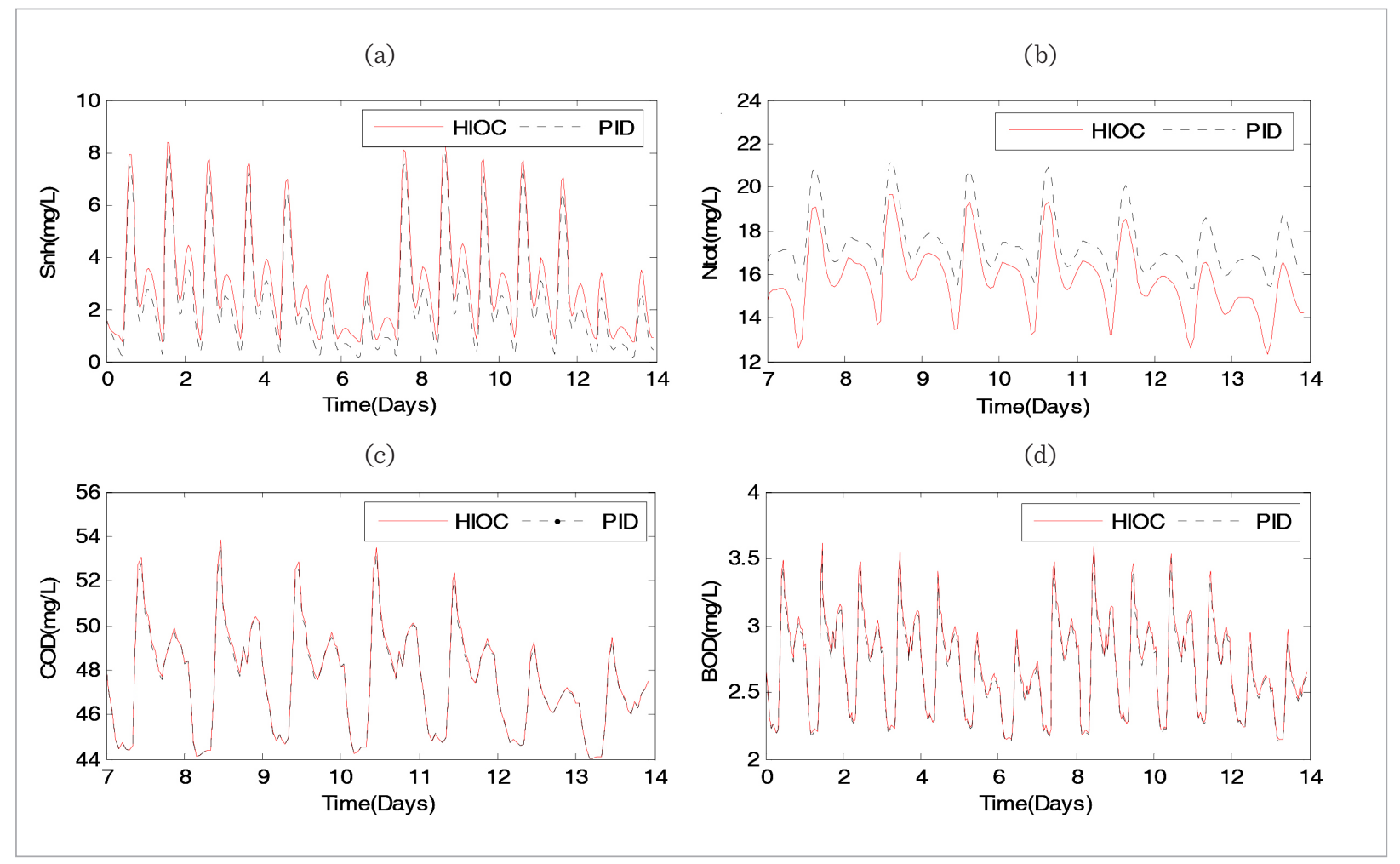


DO decreased by $30 \%$ based on the HIOC scheme, the average value of the set-point of the SNO increased by $29.4 \%$ based on the HIOC scheme, the aeration energy decreased by $17.0 \%$ based on the HIOC scheme, the pumping energy increased by $19.1 \%$ based on the HIOC scheme, the total energy consumption de- creased by $13.6 \%$ based on the HIOC scheme, and the fines decreased by $0.7 \%$ based on the HIOC scheme.

From the numerical analysis, compared to the results in [17], the results in this paper display a better performance. Due to the time lag information for optimization module in the HIOC system, the total en-

Figure 6

Optimization results of the set point values

(a)

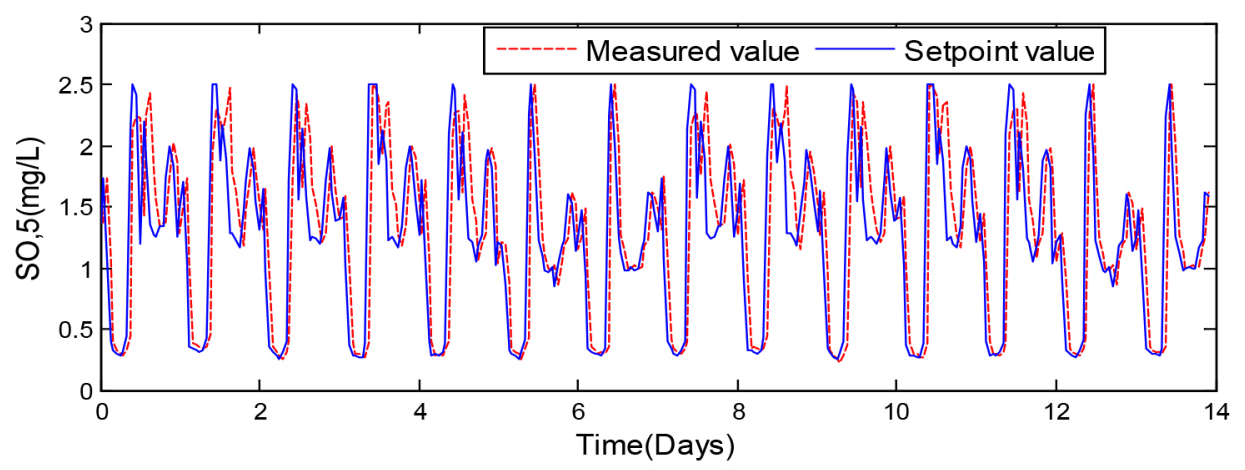

(b)

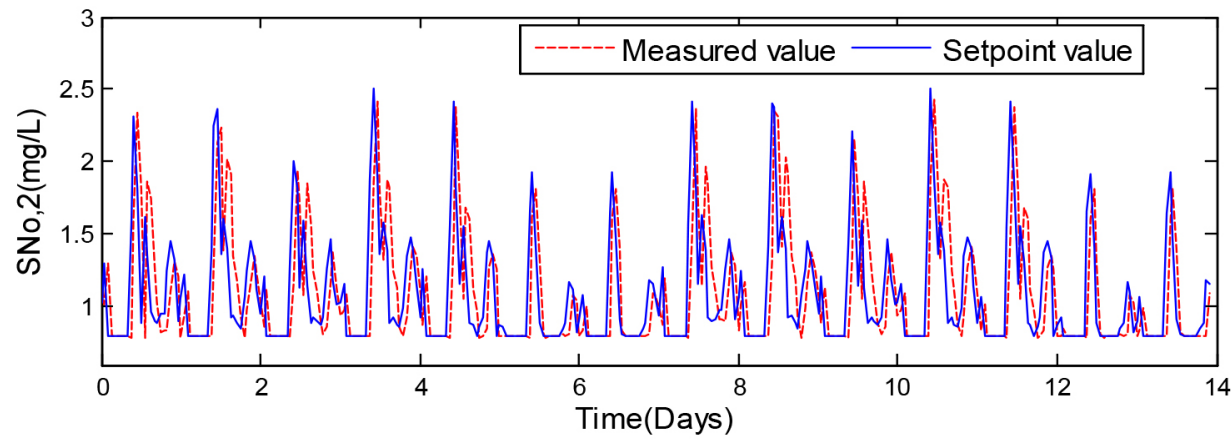

Table 4

Performance comparison between HIOC and PID

\begin{tabular}{c|c|c|c|c|c|c}
\hline & SO,5 & SNo,2 & AE & PE & Energy & Fines \\
\hline PID [17] & $2^{*}$ & $1^{*}$ & $841.1^{*}$ & $86.2^{*}$ & $927.3^{*}$ & 5129.5 \\
\hline DDAOC[17] & $1.5799^{*}$ & $1.087^{*}$ & $758.2^{*}$ & $89.8^{*}$ & $848.0^{*}$ & 5185.6 \\
\hline HIOC & 1.3999 & 1.294 & 698.4 & 102.7 & 801.1 & 5092.4 \\
\hline Up/Down & $\downarrow 30 \%$ & $\uparrow 29.4 \%$ & $\downarrow 17.0 \%$ & $\uparrow 19.1 \%$ & $\downarrow 13.6 \%$ & $\downarrow 0.7 \%$ \\
\hline
\end{tabular}

*The results are listed in the original papers. 
ergy consumption and the fines are reduced simultaneously. Thus, the total cost always reduces whatever the coefficient $a_{i}$ is chosen in Equation (14).

\section{Conclusion}

In this paper, a control optimization system based on hybrid intelligent technology is proposed to optimize the WWTP. The system includes a feed-forward compensator, a feedback supervision module, a pre-setting module and a soft-sensor module. The set-points of the dissolved oxygen concentration and nitrate nitrogen concentration are adjusted through feed-forward compensation, feedback correction and online estimation. Moreover, the delay problem in wastewater treatment process was considered to design the HIOC system. Therefore, the total energy consumption and

\section{References}

1. Andrews, R., Diederich, J., Tickle, A. B. Survey and Critique of Techniques for Extracting Rules from Trained Artificial Neural Networks. Knowledge-Based Systems, 1995, 8(6), 373-389. https://doi.org/10.1016/09507051(96)81920-4

2. Atashpaz-Gargari, E., Hashemzadeh, F., Rajabioun, R., Lucas, C. Colonial Competitive Algorithm: A Novel Approach for PID Controller Design in MIMO Distillation Column Process. International Journal of Intelligent Computing and Cybernetics, 2008, 1(3), 337-355. https://doi.org/10.1108/17563780810893446

3. Bergmann, R., Kolodner, J., Plaza, E. Representation in Case-Based Reasoning. The Knowledge Engineering Review, 2005, 20(3), 209-213. https://doi.org/10.1017/ S0269888906000555

4. Chai, T. Y., Ding, J. L., Wu, F. H. Hybrid Intelligent Control for Optimal Operation of Shaft Furnace Roasting Process. Control Engineering Practice, 2011, 19(3), 264275. https://doi.org/10.1016/j.conengprac.2010.05.002

5. Cover, T., Hart, P. Nearest Neighbor Pattern Classification. IEEE Transactions on Information Theory, 1967, 13(1), 21-27. https://doi.org/10.1109/TIT.1967.1053964

6. Cunningham, P. A Taxonomy of Similarity Mechanisms for Case-Based Reasoning. IEEE Transactions on Knowledge and Data Engineering, 2009, 21(11), 15321543. https://doi.org/10.1109/TKDE.2008.227 the fines can be reduced simultaneously by applying the proposed method. The simulations illustrate that the cogitation of this control strategy provides an effective optimal means for the large delay systems.

\section{Acknowledgments}

This work was supported by the National Science Foundation of China under Grants 61203099, 61533002 and 61225016, Beijing Nova Program under Grant Z131104000413007, China Postdoctoral Science Foundation under Grant 2014M550017, Ph.D. Program Foundation from Ministry of Chinese Education under Grant 20121103120020 and 20131103110016, Collaborative Innovation Program under Grant ZH14000177, and Beijing Municipal Education Commission Foundation under Grants km201410005001 and KZ201410005002.

7. Duch, W., Setiono, R., Zurada, J. M. Computational Intelligence Methods for Rule-Based Data Understanding. Proceedings of the IEEE, 2004, 92(5), 7771-805. https://doi.org/10.1109/JPROC.2004.826605

8. Han, H. G., Qiao, J. F., Chen, Q. L. Model Predictive Control of Dissolved Oxygen Concentration Based on a Self-Organizing RBF Neural Network. Control Engineering Practice, 2012, 20(4), 465-476. https://doi. org/10.1016/j.conengprac.2012.01.001

9. Lai, G. Y., Liu, Z., Zhang, Y., Chen, X., Chen, C. L. P. Robust Adaptive Fuzzy Control of Nonlinear Systems with Unknown and Time-Varying Saturation. Asian Journal of Control, 2015, 17(3), 791-805. https://doi. org/10.1002/asjc.921

10. Lv, Y., Yang, H. Z. A Multi-Model Approach for Soft Sensor Development Based on Feature Extraction Using Weighted Kernel Fisher Criterion. Chinese Journal of Chemical Engineering, 2014, 22(2), 146-152. https:// doi.org/10.1016/S1004-9541(14)60007-0

11. Neelamegam, P., Krishnaraj, S. Associative Neural Network and Multi Linear Regression Based Quantitative Structure Property Relationship for Modeling Viscosity of Alcohols. Asian Journal of Chemistry, 2011, 23(11), 5079 .

12. Nopens, I., Benedetti, L., Jeppsson, U., Pons, M. N., Alex, J., Copp, J. B., Gernaey, K. V., Rosen, C., Steyer, J. P., Van- 
rolleghem, P. A. Benchmark Simulation Model No 2: Finalisation of Plant Layout and Default Control Strategy. Water Science \& Technology, 2010, 62(9), 1967-1974. https://doi.org/10.2166/wst.2010.044

13. Piotrowski, R., Błaszkiewicz, K., Duzinkiewicz, K. Analysis the Parameters of the Adaptive Controller for Quality Control of Dissolved Oxygen Concentration. Information Technology and Control, 2016, 45(1), 42-51. https://doi.org/10.5755/j01.itc.45.1.9246

14. Piotrowski, R., Brdys, M. A., Konarczak, K., Duzinkiewicz, K., Chotkowski, W. Hierarchical Dissolved Oxygen Control for Activated Sludge Processes. Control Engineering Practice, 2008, 16(1), 114-131. https:// doi.org/10.1016/j.conengprac.2007.04.005

15. Piotrowski, R., Skiba, A. Nonlinear Fuzzy Control System for Dissolved Oxygen with Aeration System in Sequencing Batch Reactor. Information Technology and Control, 2015, 44(2), 182-195. https://doi.org/10.5755/ j01.itc.44.2.7784

16. Porter, B. W., Bareiss, R., Holte, R. C. Concept Learning and Heuristic Classification in Weak-Theory Domains. Artificial Intelligence, 1990, 45(1-2), 229-263. https:// doi.org/10.1016/0004-3702(90)90041-W

17. Qiao, J. F., Bo, Y. C., Chai, W., Han, H. G. Adaptive Optimal Control for a Wastewater Treatment Plant Based on a Data-Driven Method. Water Science \& Technology, 2013, 67(10), 2314-2320. https://doi.org/10.2166/ wst.2013.087

18. Qiao, J. F., Han, G., Han, H. G. Neural Network On-line Modeling and Controlling Method for Multi-Variable Control of Wastewater Treatment Processes. Asian Journal of Control, 2014, 16(4), 1213-1223. https://doi. org/10.1002/asjc.758

19. Qiao, J. F., Li, W., Han, H. G. Soft Computing of Biochemical Oxygen Demand Using an Improved T-S Fuzzy Neural Network. Chinese Journal of Chemical Engineering, 2014, 22(11), 1254-1259. https://doi. org/10.1016/j.cjche.2014.09.023

20. Shao, W. M., Tian, X. M., Wang, P. Local Partial Least Squares Based Online Soft Sensing Method for Multi-Output Processes with Adaptive Process States Division. Chinese Journal of Chemical Engineering, 2014, 22(7), 828-836. https://doi.org/10.1016/j. cjche.2014.05.003

21. Shapiro, A. M. How Including Prior Knowledge as a Subject Variable May Change Outcomes of Learning Research. American Educational Research Journal, 2004, 41(1), 159-189. https://doi. org/10.3102/00028312041001159
22. Shen, W. H., Chen, X. Q., Corriou, J. P. Application of Model Predictive Control to the BSM1 Benchmark of Wastewater Treatment Process. Computers \& Chemical Engineering, 2008, 32(12), 2849-2856. https://doi. org/10.1016/j.compchemeng.2008.01.009

23. Shen, W. H., Chen, X. Q., Pons, M. N., Corriou, J. P. Model Predictive Control for Wastewater Treatment Process with Feedforward Compensation. Chemical Engineering Journal, 2009, 155(1-2), 161-174. https://doi. org/10.1016/j.cej.2009.07.039

24. Suescun, J., Irizar, I., Ostolaza, X., Ayesa, E. Dissolved Oxygen Control and Simultaneous Estimation of Oxygen Uptake Rate in Activated-Sludge Plants. Water Environment Research, 1998, 70(3), 316-322. https://doi. org/10.2175/106143098X124948

25. Vrečko, D., Hvala, N., Kocijan, J. Wastewater Treatment Benchmark: What Can Be Achieved with Simple Control? Water Science \& Technology, 2002, 45(4-5), 127134.

26. Vrečko, D., Hvala, N., Stare, A., Burica, O., Stražar, M., Levstek, M., Cerar, P., Podbevšek, S. Improvement of Ammonia Removal in Activated Sludge Process with Feedforward-Feedback Aeration Controllers. Water Science \& Technology, 2006, 53(4-5), 125-132. https:// doi.org/10.2166/wst.2006.098

27. Wahab, N. A., Katebi, R., Balderud, J. Multivariable PID Control Design for Activated Sludge Process with Nitrification and Denitrification. Biochemical Engineering Journal, 2009, 45(3), 239-248. https://doi.org/10.1016/j. bej.2009.04.016

28. Wett, B., Ingerie, K. Feedforward Aeration Control of a Biocos Wastewater Treatment Plant. Water Science \& Technology, 2001, 43(3), 85-91.

29. Xu, F., Wang, Y. Y., Luo, X. L. Soft Sensor for Inputs and Parameters Using Nonlinear Singular State Observer in Chemical Processes. Chinese Journal of Chemical Engineering, 2013, 21(9), 1038-104\%. https://doi. org/10.1016/S1004-9541(13)60570-4

30. Zhang, H. G., Cui, L. L., Zhang, X., Luo, Y. H. Data-Driven Robust Approximate Optimal Tracking Control for Unknown General Nonlinear Systems Using Adaptive Dynamic Programming Method. IEEE Transactions on Neural Networks, 2011, 22(12), 2226-2236. https://doi. org/10.1109/TNN.2011.2168538

31. Zhou, P., Chai, T. Y., Wang, H. Intelligent Optimal-Setting Control for Grinding Circuits of Mineral Processing Process. IEEE Transactions on Automation Science and Engineering, 2009, 6(4), 730-743. https://doi. org/10.1109/TASE.2008.2011562 


\section{Summary / Santrauka}

Due to the characteristics of large lag and high nonlinearity, the optimizing operation of wastewater treatment process (WWTP) is difficult to be designed. To solve this problem, a control optimization system based on hybrid intelligent technology is proposed in this paper. This system includes a feed-forward compensator, a feedback supervision module, a pre-setting module and a soft-sensor module. To obtain the minimum energy consumption (EC) under effluent standards, the set-points of the dissolved oxygen concentration and nitrate nitrogen concentration are adjusted through feed-forward compensation, feedback correction and online estimation. Finally, the proposed approach is applied on the WWTP simulation model. Compared to the proportional-integral- derivative (PID) and data-driven adaptive optimal controller (DDAOC) methods, simulation results of the method proposed in this paper show better performance.

Dèl didelių inertiškumo ir aukšto netiesiškumo charakteristikų yra sudètinga suplanuoti optimalų nuotekų valymo procesą. Siekiant išspręsti šią problemą, straipsnyje siūloma valdymo optimizavimo sistema, pagrịsta hibridine išmaniaja technologija. Ši sistema turi postūmio kompensatorių, grịžtamojo ryšio stebẻjimo modulị, išankstinio nustatymo modulį ir programinès įrangos jutiklio modulį. Norint pasiekti mažiausią energijos suvartojimą pagal nuotekų standartus, ištirpusio deguonies ir nitratų azoto koncentracijos nustatymo taškai koreguojami taikant postūmio kompensavimą, grįžtamojo ryšio korekciją ir tiesioginị ịvertinimą. Siūlomas metodas yra pritaikomas vandens nuotekų valymo proceso simuliacijos modeliui. Palyginus su PID valdiklio ir DDAOC valdiklio metodais, straipsnyje pasiūlyto metodo simuliacijos rezultatai rodo geresnius rezultatus. 